\title{
La militarización de la muerte: guerra y religión en el Río de la Plata a comienzos del siglo XIX (1806-1820)*
}

FACUNDO Roca

Profesor en Historia en la Universidad Nacional de La Plata (Argentina). Correo electrónico: facundo. roca@yahoo.com.ar. El autor es becario doctoral de la institución mencionada. Entre sus publicaciones recientes esta "Representaciones y usos políticos de la muerte: discursos y prácticas fúnebres en la provincia de Buenos Aires (1822-1880)". En Elites rioplatenses del siglo XIX: Biografías, representaciones, disidencias y fracasos, comps. Barcos, María Fernanda y Troisi Meleán, Jorge, (La Plata: Facultad de Humanidades y Ciencias de la Educación de la Universidad Nacional de La Plata, 2018). Entre sus temas de interés se encuentran transformaciones en la religiosidad y las actitudes ante la muerte entre los siglos XVIII y XIX.

Recibido: 5 de abril de 2019

Aprobado: 10 de noviembre de 2019

Modificado: 20 de noviembre de 2019

Artículo de investigación científica

DOI: http://dx.doi.org/10.15648/hc.36.2020.9

* Este artículo forma parte del proyecto "Saberes y nichos profesionales en la construcción de los Estados-Nación. Argentina y Brasil (1850-1930)" financiado por la Universidad Nacional de La Plata (Argentina).

Esta publicación está bajo una licencia Creative Commons Reconocimiento-NoComercial 4.0 
La militarización de la muerte: guerra y religión en el Río de la Plata a comienzos del siglo XIX (1806-1820)

\title{
Resumen
}

El propósito de este artículo consiste en analizar el impacto que tuvieron las guerras de principios del siglo XIX, en el ámbito específico de las actitudes colectivas ante la muerte. Las diferentes fuentes trabajadas revelan el profundo impacto que tuvo el continuado estado de guerra, al que se vio sometido el Río de la Plata a partir de 1806, en cuanto a la forma de entender y enfrentar la muerte, así como la ruptura que suponía esta nueva sensibilidad con respecto al viejo modelo barroco. Asimismo, identificamos diversos mecanismos y dispositivos destinados a resignificar la muerte dentro de este contexto en particular.

Palabras clave: Guerra, muerte, religión, Río de la Plata, siglo XIX.

\section{Militarization of death: war and religion in the Río de la Plata at the beginning of the 19th century (1806-1820)}

\begin{abstract}
The purpose of this article is to examine the impact of the wars in the early nineteenth century, particularly in the field of collective attitudes towards death. Different sources reveal the profound impact of the continued state of war, in which the Río de la Plata was subjected since 1806. This, in regard to the way of understanding and facing death, as well as the rupture implications in this new sensitivity related to the old baroque model. We also identify different mechanisms and devices designed to resignify death within this particular context.
\end{abstract}

Key words: War, death, Río de la Plata, 19th Century.

\section{A militarização da morte: guerra e religião no Rio da Prata no início do século XIX (1806-1820)}

\section{Resumo}

O objetivo deste artigo é analisar o impacto das guerras no início do século XIX, no contexto específico das atitudes coletivas diante da morte. As diferentes fontes trabalhadas revelam o profundo impacto que teve o estado continuado da guerra, ao qual o Rio da Prata foi submetido a partir de 1806, a respeito da forma de compreender 
e enfrentar a morte, bem como a ruptura que essa nova sensibilidade acarretou em relação ao antigo modelo barroco. Também identificamos diferentes mecanismos e dispositivos projetados para ressignificar a morte dentro desse contexto particular.

Palavras-chave: Guerra, morte, Rio da Prata, século XIX.

\section{La militarisation de la mort: guerre et religion dans le Río de la Plata au début du XIXe siècle (1806-1820)}

\section{Résumé}

Le but de cet article est d'analyser l'impact des guerres du début du XIXe siècle dans le domaine spécifique des attitudes collectives devant la mort. Les différentes sources travaillées révèlent l'impact profond de l'état de guerre permanent, auquel le Río de la Plata a été soumis à partir de 1806, sur la manière de comprendre et de faire face à la mort, ainsi que la rupture que cette nouvelle sensibilité implique par rapport à l'ancien modèle baroque. Nous identifions également divers mécanismes et dispositifs conçus pour resignifier la mort dans ce contexte particulier.

Mots clés: Guerre, mort, Río de la Plata, XIXe siècle

\section{INTRODUCCIÓN: GUERRA Y BUENA MUERTE.}

Con el desembarco de las tropas británicas del general Beresford en las costas de Quilmes, en junio de 1806, el fenómeno de la guerra adquiere una nueva dimensión en el Río de La Plata. Hacia fines del período colonial, las fuerzas milicianas jugaban un papel crucial dentro del orden social, tanto en la ciudad como en la campaña, y contaban con su propia experiencia y tradición militar. Sin embargo, a partir de las invasiones inglesas, la sociedad rioplatense entra en una nueva fase de militarización, en la cual las fuerzas ya existentes se incrementan de manera exponencial. En poco tiempo Buenos Aires se transformará en una "villa en armas". La guerra habrá de convertirse en un estado casi permanente durante las próximas décadas, redefiniendo completamente a la sociedad rioplatense en su conjunto. La experiencia bélica habrá de tener consecuencias muy profundas y duraderas en los más diversos aspectos de la vida social, desde los económicos hasta los políticos y culturales. 
Diferentes investigadores, sobre todo a partir de los trabajos de Tulio Halperín Donghi ${ }^{1}$, han señalado la importancia que tuvo el proceso de militarización en los acontecimientos que condujeron a la revolución de mayo de 1810. Según Halperín, la irrupción de las milicias urbanas a partir de 1806 alteró definitivamente el equilibrio de poder a escala local, promoviendo un nuevo espíritu democrático e igualador y generando liderazgos alternativos dentro de la propia élite criolla. La militarización de la sociedad porteña también condujo a una "redistribución de ingresos", al transferir "riqueza de los grupos sociales más elevados a los más bajo"2. Asimismo, esta "cultura de la guerra" tuvo un impacto muy profundo y duradero en el ámbito político, con la consolidación del nuevo modelo de "ciudadano en armas".

En este trabajo abordaremos otro aspecto, quizá menos evidente y un tanto tangencial, dentro de esta gran transformación de la sociedad rioplatense. Nuestro objetivo consiste en analizar cómo la guerra afecta la actitud del hombre ante la muerte y cómo ésta se carga y enviste de nuevas connotaciones y significados. Algunos conceptos en particular, como el de martirio, heroísmo y gloria habrán de jugar un papel privilegiado, no sólo en el discurso público sino también en la percepción de la propia muerte. Como señala María Alejandra Fernández, "la guerra revolucionaria introduce algunos ribetes novedosos en las apreciaciones culturales acerca de la buena y la mala muerte, pues impone una nueva forma de morir en el Río de la Plata"3. Dar la vida por la patria se convertirá en un imperativo social y en un horizonte de realización personal que contribuirá a desplazar o mitigar la incertidumbre de la vida militar, así como el temor a la muerte. La construcción de un arquetipo de muerte heroica permitirá legitimar la acción guerrera, así como la

1 Tulio Halperin Donghi. Revolución y Guerra. Formación de una élite dirigente en la Argentina criolla (Buenos Aires: Siglo XXI, 1994).

2 Tulio Halperín Donghi, "Militarización Revolucionaria en Buenos Aires, 1806-1815”, en El ocaso del orden colonial en Hispanoamérica. (Buenos Aires: Sudamericana, 1978), 157.

3 María Alejandra Fernández, "Muerte y pedagogía política durante la Revolución: Buenos Aires, 18101812", en Muerte, política y sociedad en la Argentina, eds. Sandra Gayol y Gabriel Kessler (Buenos Aires: Edhasa, 2015), 35. A diferencia del enfoque propuesto en este artículo, el trabajo de Fernández se concentra en la dimensión política de la muerte y en su uso pedagógico, en tanto contraejemplo, particularmente en el caso de los contrarrevolucionarios cordobeses de 1810 y de los conspiradores de 1812. 
legitimación de ésta contribuirá a garantizar la heroicidad de la muerte en combate. Asimismo, la justificación de la guerra como una expresión de la providencia y la voluntad divina permitirá acallar la conciencia del soldado, legitimando la aniquilación del enemigo.

El temor a la muerte ha sido siempre inescindible de la experiencia guerrera. En torno a ella se articulaban una gran variedad de discursos y dispositivos que procuraban conjurar y aquietar las ansiedades del soldado, sujetar su espíritu y dominar su cuerpo. Si el miedo se apoderaba del combatiente y devenía en pánico, y si éste se volvía colectivo, toda la empresa bélica podía ponerse en riesgo. El miedo a la muerte se erguía como una amenaza omnipresente, difícil de conjurar y altamente peligrosa. Pero no era simplemente el miedo al fin de la vida, en tanto cese de la existencia biológica, lo que aguijoneaba la atribulada conciencia del soldado. Era el miedo a la "mala muerte", a la perdición y condenación eterna lo que realmente aterrorizaba al hombre de principios del siglo XIX. La concepción cristiana de las postrimerías, especialmente en su versión barroca colonial, hacía aún más intolerable la muerte súbita, inconfesa y anónima del soldado.

En las sociedades de Antiguo Régimen el momento y la forma de la muerte eran considerados un factor decisivo para la salvación del alma. La imagen de un hombre agonizante postrado en su lecho, rodeado por una multitud de amigos y familiares y asistido por un clérigo situado en su cabecera, expresaba el arquetipo perfecto de la "buena muerte"4. Esta escena de origen medieval va a conservar un fuerte arraigo bajo el influjo de la piedad barroca, a lo largo de los siglos XVII y XVIII. La cama se constituía en la máxima expresión de esa muerte lenta y previsible, que daba tiempo al moribundo para "descargar su conciencia" y enmendar sus faltas. 5 El "buen morir" era una condición indispen-

4 Sobre la "buena muerte" y sus modulaciones históricas, véase Philippe Ariès, El hombre ante la muerte (Madrid: Taurus, 1984).

5 Según Philippe Ariès, "el lecho era el lugar inmemorial de la muerte" y "lo siguió siendo hasta que dejó de ser lecho (...), para convertirse" en un "material tecnológico de hospital". Philippe Ariès, El hombre, 96. En el mismo sentido, Isabel Cruz de Amenábar señala que "el lecho tenía entonces una connotación simbólica como el lugar del reposo, del amor, de la enfermedad y de la muerte (...). Durante la época barroca, la cama era una especie de altar donde se inmolaba la vida del moribundo". Isabel Cruz de Amenábar, La Muerte: Transfiguración de la Vida (Santiago de Chile: Ediciones 
sable para subsanar las faltas cometidas en vida y ponerse en "carrera de salvación”. Estas prácticas ritualizadas incluían la recepción de los últimos sacramentos, la redacción del testamento y la adopción de gestos y actitudes destinados a transmitir la resignación, el abandono y la abnegación del moribundo ante el cumplimiento de la voluntad divina. Asimismo, la agonía era percibida como una instancia necesaria, que servía al moribundo para "poner sus asuntos en orden" y despedirse del "mundo".

Por el contrario, la muerte repentina, violenta o "desastrada" era indeseable y temida, ya que no permitía al hombre prepararse y tomar los recaudos correspondientes, tanto espirituales como terrenales. Las personas expuestas a peligros graves o riesgo cierto de muerte solían encomendarse a Santa Bárbara, patrona de los artilleros y protectora contra la muerte repentina. Según el imaginario popular, esta santa no dejaba que sus devotos murieran inconfesos y sin haber recibido el preciado viático. El jesuita Juan Eusebio Nieremberg, uno de los máximos representantes del "tenebrismo" contrarreformista, recordaba a los fieles que era mejor morir prevenido y con tiempo que de forma repentina e inesperada:

"Dà gracias à Dios que mueres en tu cama, no ahogado ni despeñado, ò herido en un camino: dà gracias à Dios que mueres despacio, y con tiempo para reconciliarte con tu Criador, y ajustar con èl las quentas: dà gracias à Dios que mueres, sabiendo que te mueres, que es gran dicha. O quántos ay en los infiernos, que si tuvieran la suerte que tu de morir en una cama y avisados de su peligro, se huvieran salvado!"’6.

Sin embargo, este modelo canónico de buena muerte planteaba un problema particularmente grave para la Iglesia así como para buena parte de su feligresía: ¿Qué sucedía con los muertos en combate? ¿Qué pasaba con su alma? ¿Cómo compatibilizar este ideal de muerte serena y apacible con el final violento de miles y miles de soldados, muchos de los cuales habían combatido con la venia o bajo el estandarte del Papa- 
do?; Desde los primeros siglos del cristianismo, la Iglesia se había visto confrontada a estas inquietantes preguntas, que se enlazaban con otra cuestión no menos espinosa e incómoda para la jerarquía eclesiástica: la propia legitimidad de la guerra dentro de la cosmovisión cristiana. Aunque el quinto mandamiento compelía al cristiano a "no matar", la Iglesia había procurado no hacer de éste un mensaje estrictamente pacifista. Las sagradas escrituras también estaban colmadas de guerras "santas y justas", a las que se podía apelar en cualquier momento como fuentes de legitimidad. La muerte en combate, especialmente en el marco de las cruzadas y luego en las guerras de religión, era asimilada con el martirio y auguraba la salvación segura de quien había dado su vida por la causa de Dios. De esta forma, la muerte violenta perdía su condición traumática y tormentosa y se transformaba en un camino cierto a la bienaventuranza eterna.

\section{El Dios de la guerra: Devoción y Piedad en los ejérCitos RIOPLATENSES.}

\section{"Sed un hombre fuerte, pero emplead vuestro valor en una guerra del agrado del Señor".}

Dar la vida por la patria sólo tenía sentido en la medida en que la causa de la Patria fuera también la causa de Dios. Como señalaba el clérigo Valentín Gómez en 1821, el cristiano sólo debía emplear su valor "en una guerra del agrado del Señor" (et praeliare bella Domini). En las invasiones de 1806 y 1807, la legitimidad de la guerra se encontraba garantizada por la asimilación de los ingleses con los enemigos no sólo del Rey sino también de la fe. Francisco Antonio Letamendi, mayordomo de la cofradía del Rosario y apoderado de Santiago de Liniers, afirmaba en 1807 que había sido el celo religioso del militar francés el que lo había decidido a embarcarse rumbo a Montevideo para planear la reconquista. Según Letamendi, Liniers "se confirmó en el plausible proyecto de la reconquista por un impulso de religión, cual fue observar que el

7 Valentín Gómez, "Elogio fúnebre del benemérito ciudadano Manuel Belgrano, ilustre miembro de la Primera Junta Gubernativa" (1821), en El clero argentino, de 1810 a 1830 (Buenos Aires: Imprenta de M. A. Rosas, 1907), 96. 
primer domingo de julio de 1806 no saliese la procesión acostumbrada que se hace al Redentor Sacramentado por evitar los ultrajes de los herejes que dominaban". En sus Romances históricos de la Reconquista y Defensa de Buenos Aires [1807], el sacerdote Pantaleón Rivarola, también otorgaba un rol preponderante al celo religioso de Liniers:

"siente un fuego que le abrasa, siente un ardor que le quema, un celo que le devora, una llama que le incendia, un furor que le transporta por el Dios de cielo y tierra. Los espíritus vitales nuevo ardor dan a sus venas, y allí mismo se resuelve a reconquistar la tierra para que el Dios de la Gloria, Señor de toda grandeza sea adorado como antes descubierto y sin la pena de verle expuesto al desprecio de gente insana y soberbia"9.

En sus versos, el poeta rioplatense hace de Liniers poco menos que un nuevo cruzado en defensa de la fe. Lo cierto es que el futuro virrey encomendó sus hombres a la Virgen del Rosario, le prometió las insignias del enemigo y mandó realizar sufragios en su honor durante todo el tiempo que duraron los preparativos. El rezo del rosario se extendía por la ciudad como un escudo protector, mientras que los soldados portaban sus escapularios a modo de distintivo. En agradecimiento por

8 Cayetano Bruno, La Virgen Generala. Estudio documental (Rosario: Ediciones Didascalia, 1994), 141.

9 Alberto Mario Salas, Crónica y diario de Buenos Aires: 1806-1807 (Buenos Aires: Ediciones Biblioteca Nacional, 2013), t. I, 202. 
la victoria, Liniers hizo entrega de los trofeos el día 24 de agosto, en una fiesta de la que participaron el obispo, el cabildo y la Real Audien$\mathrm{cia}^{10}$. El libro de actas de la cofradía del Rosario deja constancia de este solemne acto:

"Agradecido por los favores que le dispensó María Santísima del Rosario en todas las acciones, y en cumplimiento de su promesa, el día 24 de dicho mes de agosto, obló con una solemnísima función... las cuatro banderas, dos del regimiento número 71, y dos de Marina, que tomó a los ingleses, confesando deberse toda la felicidad de las armas de nuestro amado Soberano al singular y visible patrocinio de Nuestra Señora del Rosario o de las Victorias"11.

Los sufragios y promesas constituían actos propiciatorios que tenían por objeto lograr el favor y la protección de la divinidad. Estas muestras de devoción incluían la bendición de los estandartes y banderas de los diferentes regimientos, al igual que las grandes ceremonias públicas, como la que ocurrió en Buenos Aires el 15 de enero de 1807. Según Beruti, en esa oportunidad todas las tropas se reunieron para escuchar al obispo, que ofició la misa en

"un magnifico Tavernaculo de 4 frentes, q. ${ }^{e}$ p. ${ }^{a}$ llegar al pie de la mesa del altar, tenia que subir p. ${ }^{r} 12$, gradas espaciosas cubiertas de primorosas alfombras, el que se puso en medio del sentro del Exto, no haviendo quedado ninguno sin haver visto decir la misa, por motivo de estar el

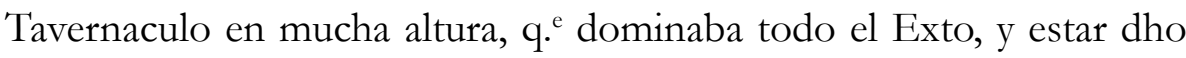
Tavernaculo avierto $\mathrm{p} .{ }^{\mathrm{r}}$ los quatro frentes. Al principiar el S. ${ }^{\text {to }}$ Sacrificio se hizo una descarga gral de fusileria, á q. ${ }^{\mathrm{n}}$ siguió la artilleria, al Sanctus otra, y otra al fin"12.

A los eclesiásticos les tocaba la ardua tarea de hacer de la guerra una causa al servicio de la voluntad divina, así como un instrumento de su justicia. En un sermón pronunciado en Buenos Aires hacia 1808, en

10 Juan Manuel Beruti, "Memorias curiosas", Revista de la Biblioteca Nacional No. 23. (1942): 143.

11 Citado en Cayetano Bruno, La Virgen Generala, 155.

12 Juan Manuel Beruti, "Memorias curiosas", 147. 
conmemoración de la "gloriosa defensa" de la capital, el predicador señalaba que la guerra, lejos de ser contraria al designio de Dios, era un "instrumento de su justicia"13. El orador definía a la guerra como un "monstruo que se alimenta de sangre humana, que lleva por todas partes el horror, el estrago, la desolación, la muerte". Sin embargo, también este "monstro" tenía una razón de ser dentro de la economía de la salvación. La guerra, según este eclesiástico, era "el azote más temible de la divina justicia para castigar nuestros delitos"14. Sin embargo, Dios no abandonaba a los justos, ya que a ellos les tenía reservada la victoria.

La legitimidad de la guerra contra estos "crueles y ambiciosos" enemigos era reforzada a través de diversos argumentos y a partir de una retahíla de analogías bíblicas. El orador comparaba la heroica defensa de Buenos Aires con las grandes victorias del pueblo judío, especialmente la de los hebreos sobre las fuerzas del Faraón: “¿Quién no ve que esta portentosa maravilla de la antigüedad, se halla visiblemente renovada en nuestros tiempos en la defensa de esta ciudad en 5 de julio de 1807 (...)?"15. El predicador iba aún más lejos y señalaba que la victoria porteña era "tan digna de inmortal memoria como lo fue la libertad de los Israelitas". El paralelismo era evidente: de un lado el "Pueblo de Dios" y del otro lado sus "poderosos enemigos". No sólo la guerra era una causa divina sino que el desenlace mismo poseía un carácter milagroso ¿Cómo explicar si no la victoria de "unos hombres para quienes era absolutamente desconocido el estruendo marcial, el manejo de las armas y evoluciones militares"? ${ }^{16}$. La retórica belicista se complementaba con ocasionales apelaciones a la historia clásica, como la comparación de Buenos Aires con una "nueva Numancia". Todo el conocimiento y la elocuencia del clero, en su faceta más apologética y propagandística, debía ponerse al servicio de la exaltación de la acción bélica.

Si la guerra era un instrumento de la voluntad divina, entonces, dejar la vida en ella (e incluso matar en combate) era otra forma de cumplir

13 Archivo General de la Nación Argentina (AGNA), Sala VII, Biblioteca Nacional, leg. 353, pieza 6131, s/f. (ca. 1808), sin numeración.

14 AGNA, Sala VII, Biblioteca Nacional, leg. 353.

15 AGNA, Sala VII, Biblioteca Nacional, leg. 353.

16 AGNA, Sala VII, Biblioteca Nacional, leg. 353. 
con los designios de Dios. Según el orador anónimo de 1808, era la divinidad misma la que infundía el heroísmo en los soldados y aplacaba el temor a la muerte: "Dios es únicamente el que infunde en los hombres aquella heroicidad con que se arrostran los mayores peligros y se desprecian con valor los funestos horrores de la muerte"17. En la visión del predicador, el desprecio por la vida que demostraba el soldado, su abandono al azar del combate o al designio divino, era muy similar al abandono o rechazo del "Mundo" que practicaba el religioso. Ambos despreciaban los valores mundanos o terrenos, las comodidades del "siglo" y el amor a la vida, en aras de una gloria futura, ya fuera éste terrena o celestial. Si la gloria terrenal era la recompensa de los sobrevivientes, la "gloria eterna" era la de los difuntos. Aquellos que "gloriosamente murieron por la patria" tenían el privilegio de gozar de la "vida inmortal y bienaventurada"18.

Pero a diferencia de lo ocurrido en las invasiones inglesas, los revolucionarios de Mayo no podían afirmar inequívocamente que contaran con el auxilio y el beneplácito divino, o para decirlo en términos de Valentín Gómez, que pelearan "una guerra del agrado del Señor". Durante las guerras de independencia, esa legitimidad y protección se encontraba dividida y sometida a una feroz disputa. El gobierno revolucionario procuró obtener el apoyo de los eclesiásticos y los instó a que proclamaran desde el púlpito la santidad de su causa, inflamando los ánimos de sus feligreses. Lo mismo hicieron los realistas, que contaban entre sus filas al propio obispo de Córdoba, monseñor Rodrigo de Orellana. Las acusaciones de herejía y sacrilegio cruzaban de un bando al otro y tenían por objeto desacreditar al enemigo e investirse de la legitimidad que otorgaba la causa divina.

Un sermón pronunciado en Santiago del Estero, poco después de la batalla de Tucumán, e impreso en Buenos Aires hacia fines de 1812, era explícito en este punto. Su autor, el cura revolucionario Juan Antonio Neirot, justificaba la guerra como una rebelión contra la injusta tiranía española:

17 AGNA, Sala VII, Biblioteca Nacional, leg. 353.

18 AGNA, Sala VII, Biblioteca Nacional, leg. 353. 
"Tuvieron los Incas emperadores que más parecieron padres que señores: vivos eran amados y muertos llorados. Pero en medio del goce de estas felicidades aparecen los peninsulares de Europa. ¡Ah desgraciados días; Desde este momento comenzó el paraíso americano a transformarse en el más lamentable teatro de sangre, de ruina y desolación. Introduxeron su dominación no solo tiránica en el título, sino también en el exercicio" 19 .

Para apuntalar su causa, el predicador no dudaba en valerse de autoridades de la propia Iglesia española, como Fray Bartolomé de las Casas o el benedictino ilustrado Benito Jerónimo Feijoó. Según Neirot, era la propia intervención divina la que le había concedido la victoria a los patriotas: "Aquel gran Señor (...) es el mismo que destinó el glorioso día 24, en que nuestra madre la Iglesia celebra la aparición de la SSma. Virgen, para sepultar en la heroyca ciudad del Tucumán la tiranía y la esclavitud"20. La empresa revolucionaria era la consumación inevitable de la divina providencia. Como diría años más tarde Fray Cayetano Rodríguez, "nada había más natural que el desprendimiento de la inmensa porción del nuevo mundo de una pequeña parte del antiguo"21.

Esta disputa por la protección divina tampoco era privativa del Río de La Plata. En México, la revolución había sido encabezada por dos curas, Miguel Hidalgo y José María Morelos, y aunaba reclamos de raigambre popular con otros muy caros a la Iglesia hispanoamericana, como el respeto a la inmunidad eclesiástica. En Nueva España ambos ejércitos, el revolucionario y el independentista buscaron la protección y el amparo divino, los primeros poniéndose bajo el estandarte de la Virgen de Guadalupe y los segundos bajo el de la Virgen de los Remedios. Como señala Serge Gruzinski,

19 Juan Antonio Neirot, Oración fúnebre que en las solemnes exequias de los valientes soldados que murieron en la defensa de la patria en la ciudad del Tucumán... (Buenos Aires: Imprenta de Niños Expósitos, 1812), 5.

21620 Juan Antonio Neirot, Oración fúnebre, 3.

21 Cayetano Rodríguez, "Elogio fúnebre del benemérito ciudadano, ilustre miembro de la Primera Junta Gubernativa ...Don Manuel Belgrano” [1821], en El clero argentino, de 1810 a 1830 (Buenos Aires: Imprenta de M. A. Rosas, 1907), 125. 
"parece haber sido una lucha que, a su manera, remató en una "guerra de las imágenes". Esto es, sin duda, violentar la historia, pero esa interpretación tiene una parte de verdad. Dícese que los españoles llegaron a odiar a la Virgen del Tepeyac hasta el punto de fusilar una de sus efigies y profanar algunas otras"22.

También en el Río de La Plata ambos bandos afirmaban tener a Dios y a la Virgen de su lado. En 1812, luego de la batalla de Tucumán, Manuel Belgrano entregó su bastón de mando a la Virgen de la Merced, proclamándola generala del Ejército del Norte ${ }^{23}$. Desde Buenos Aires se enviaron cuatro mil pares de escapularios de esta advocación para ser repartidos entre todo el ejercito. Como señala Fernando Gómez, “considerando la multiplicidad de uniformes, el escapulario se convirtió en un distintivo que unificaba al interior del ejército" 24 . En sus memorias, José María Paz relata la favorable impresión que infundió el ejército revolucionario a sus oponentes realistas, luego de la batalla de Salta: "la opinión de impíos y herejes en que nos tenían se había disipado al ver nuestros escapularios y otros signos religiosos" 25 . La elección de la Virgen como generala y patrona, así como las oraciones y sufragios en su altar eran una manera de implorar la protección divina para el momento de la batalla. Mientras que Belgrano había puesto a su ejército bajo el patronazgo de la Virgen de la Merced, San Martín hizo lo propio, en 1817, con Nuestra Señora del Carmen. Doña Manuela Guiñazú de Encinas, vecina de Mendoza, recordaba haber

“oído declarar a su señora madre que asistió (...) a la proclamación de la Virgen del Carmen que se veneraba en el templo de San Francisco,

22 Serge Gruzinski, La guerra de las imágenes. De Cristóbal Colón a Blade Runner (1942-2019) (México: Fondo de Cultura Económica, 1994), 205.

23 Sobre el fenómeno de las Vírgenes Generalas, véase el excelente trabajo de Pablo Ortemberg, "Las vírgenes generalas: acción guerrera y práctica religiosa en las campañas del Alto Perú y el Río de la Plata (1810-1818)", Boletín del Instituto de Historia Argentina y Americana "Dr. Emilio Ravignani" No. 35-36 (2011-2012).

24 Fernando Gómez, Guerra y movilización popular en tiempos revolucionarios. Una perspectiva desde la Batalla de Tucumán (Buenos Aires, Foros de historia política, 2013), http://historiapolitica. com/datos/foros/foro_sectpopulares_gomez.pdf (consultado el 3/4/2019).

25 José María Paz, Memorias póstumas (Buenos Aires: Imprenta de la Revista, 1855), 87. 
como patrona del ejército de San Martín, y recordaba... que todos los soldados ostentaban en el pecho el escapulario del Carmen"26.

La elección de la Virgen del Carmen y de su escapulario resulta altamente significativa. Esta devoción mariana era famosa por su poder terapéutico y sus milagrosas curaciones. Además, se le atribuía el poder de sacar a sus devotos del purgatorio en el primer sábado después de su muerte. Como señala María Elena Barral, el escapulario del Carmen era "una especie de amuleto protector que bien, o prevenía contra la muerte, o aseguraba que nadie que muriese con él podría sufrir penas eternas" ${ }^{27}$. Como demuestran múltiples testimonios, los soldados no eran ajenos al temor que infundía la muerte y el más allá. El general José Matías Zapiola, veterano de las batallas de Chacabuco y Maipú, reconocía antes de morir que siempre había llevado consigo un escapulario de Nuestra Señora del Carmen junto con una medalla de la Virgen de Luján, que "considera como un precioso talismán que lo guardaba de tantos peligros a que se ve expuesto" 28 . La protección de la Virgen y de Dios alejaba el temor a la muerte y aquietaba la conciencia del soldado. Además, este patrocinio divino contribuía a aumentar la fortaleza y cohesión interna de un ejército constantemente asediado por las deserciones y eventual presa del pánico y la desintegración.

\title{
2. “¡O JUREMOS CON GLORIA MORIR!”: LA MUERTE EN COMBATE Y LA CONSTRUCCIÓN DE LA HEROICIDAD.
}

"La guerra de la independencia nos ha dejado la manía ridícula y aciaga del heroísmo"

\author{
Juan B. Alberdi ${ }^{29}$.
}

En el contexto de la guerra, la muerte se transforma en una amenaza recurrente y peligrosamente cercana. El contacto con esas experiencias

26 Cayetano Bruno, La Virgen Generala, 99. Las bastardillas corresponden al original.

27 María Elena Barral, De sotanas por la Pampa. Religión y sociedad en el Buenos Aires rural tardocolonial. (Buenos Aires: Prometeo, 2007), 182.

21828 Cayetano Bruno, La Virgen Generala, 341.

29 Alejandro Rabinovich, "La gloria, esa plaga de nuestra pobre América del Sud. Ethos guerrero en el Río de la Plata durante la Guerra de la Independencia, 1810-1824”. Nuevo Mundo Mundos Nuevos, Débats (2009): párr. 3. 
traumáticas y la forma en que éstas inciden en la psiquis del sujeto es motivo de un interés cada vez mayor, tanto por parte de los estados como desde diversas disciplinas científicas. A medida que se multiplican las bajas psiquiátricas entre los ejércitos modernos, los psicólogos y médicos militares dedican cada vez más tiempo y recursos al estudio de los efectos concretos que produce el contacto reiterado con la muerte en el contexto del combate. También los polemólogos han advertido el peso que poseen las pérdidas en las propias filas y su efecto en la subjetividad del combatiente. El espectáculo de la muerte, en su forma más cruenta y descarnada (efusión de sangre, cabezas cercenadas, cuerpos desmembrados), generaría un efecto psicológico acumulativo de desastrosas consecuencias. Como señala Alejandro Rabinovich, "llegaría así un punto en que el soldado no puede sino obsesionarse con el pensamiento de la propia muerte hasta romper todos los automatismos del entrenamiento militar" ${ }^{30}$. Más allá de este umbral, el sujeto se entregaría al pánico y abandonaría todas las restricciones impuestas por su yo consciente.

Sin embargo, no todos poseían el mismo nivel de tolerancia ni se veían afectados de la misma forma en estas difíciles circunstancias. Nadie era ajeno al temor, pero muchos seguían combatiendo a pesar de éste. Como señala John Keegan, en estas circunstancias críticas podía entrar en juego otro factor: "el miedo a ser considerado un cobarde y, en consecuencia, ser despreciado" 31 . A su vez, estos comportamientos no dependían exclusivamente de la subjetividad individual del soldado, sino que involucraban una serie de dispositivos disciplinarios y de control. Por ejemplo, los obedientes soldados prusianos "aguardaban la carnicería en fila, inertes, de pie y en silencio, a veces durante horas" 32 , mientras que los cosacos, que Clausewitz despreciaba, rehuían los enfrentamientos directos y no tenían escrúpulos en huir del campo de batalla. Las diferentes formas de enfrentar la muerte se correspondían con distintas "éticas guerreras" y dependían del nivel de cohesión interna de cada ejército. (1811) (Buenos Aires: Sudamericana), 27.

31 John Keegan, El rostro de la batalla (Madrid: Turner, 2016), 27.

32 John Keegan, Historia de la Guerra (Barcelona: Planeta, 2005), 28. 
En el seno de las sociedades guerreras se desarrollaban diversos mecanismos de gestión y resignificacion de la muerte, que procuraban hacer más tolerables las grandes tragedias, tanto personales como colectivas. En los días posteriores a la Reconquista de Buenos Aires, al igual que luego de la defensa de 1807, se multiplicaron las exequias y ceremonias fúnebres por el alma de los caídos. Estas celebraciones tenían por objeto resignificar la muerte de los soldados fallecidos, al mismo tiempo que propendían a acrecentar la cohesión interna de la sociedad y de los diversos regimientos afectados. La muerte individual de cada uno de los combatientes adquiría sentido como parte de un sacrificio colectivo, coronado tanto por la gloria militar como por la bienaventuranza eterna. Como señala Rabinovich, "se destaca sorprendentemente la centralidad de la gloria como objeto de coronamiento, como aliada de la muerte" 33 . En estas honras fúnebres no se escatimaban recursos, ya que a través de ellas se buscaba dar cuenta de la hazaña alcanzada por cada cuerpo, así como fortalecer y confortar el ánimo de una sociedad extenuada por el esfuerzo de la guerra. Por ejemplo, las exequias celebradas en 1807 a instancias del Cuerpo de Marina deben haber tenido, por su boato y dimensiones, un impacto muy profundo en los concurrentes. En sus memorias, Beruti les dedica un extenso y minucioso recuento:
"Se puso un famoso Tumulo de altura de 26., Var. el que se pusó debajo dela media naranja de quatro frentes, y en todos se decia misa, estando en él mas de 400. luces, entre achas y velas con primorosa orn coloca- das. Oficiaron los Cantos los Cantores de la Iglesia Cathedral, àson de música fúnebre y solfa. La Iglesia estaba toda obscurecida, y las quatro columnas del Crucero enlutadas con el Pulpito de paños negros. Verda- deram. ${ }^{\text {te }}$ fueron funerales propios p. ${ }^{\text {a }}$ una persona Real" 34 .

Las exequias se entrelazaban con las muestras de júbilo y algarabía, en una sucesión casi interminable. El ignoto autor del Diario de la defensa de Buenos Aires remarcaba esta extraña combinación: "este contraste de afectos de tristeza y placer, continúa siendo siempre el objeto inseparable de nuestra atención, porque la alternada serie de acciones, entie-

\footnotetext{
33 Alejandro Rabinovich, La gloria, esa plaga de nuestra, 2.

34 Juan Manuel Beruti, "Memorias curiosas", No. 24: 401.
} 
rros, exequias y oraciones fúnebres, nos precisa ser continuos asistentes de estos actos"35. Cada cuerpo ofrecía su propia ceremonia y rivalizaba con los demás en la pompa y lujo de las exequias, así como en el número de combatientes que se habían sacrificado en aras de la victoria. Este espíritu de grupo reflejaba un sentimiento de pertenencia muy particular. John Keegan ha identificado esta conducta con el "tribalismo" que se observa en las sociedades primitivas. Según Keegan, la construcción identitaria del soldado no descansaba tanto en "el ejército" como totalidad abstracta, sino en cada uno de los regimientos: "los regimientos se significaban por encima de todo por su carácter, y era ese carácter el que los hacía organizaciones de combate cuya eficacia en la lucha testimoniaban todas aquellas medallas y cruces que veía por doquier"36. Las exequias públicas, convertidas en grandes manifestaciones de luto colectivo, tenían precisamente el objetivo de fortalecer y consolidar esa identidad y carácter grupal. Asimismo, las manifestaciones luctuosas eran una instancia de visibilización y de disputa por la porción de gloria que le correspondía a cada uno de los regimientos involucrados. Como señala Rabinovich, "la imagen de la hazaña, del acto de guerra, debía o bien ser vista directamente o transmitida en relato, sublimada en arte, simbolizada en escudos, acreditada en trofeos, hasta ser finalmente "vista" también por los contemporáneos ausentes del campo de batalla"37.

Desde el púlpito, la muerte del soldado era glorificada y presentada como un sublime sacrificio. A ellos se les prometía la memoria y el recuerdo de las generaciones futuras, así como el goce de la bienaventuranza eterna. En estos términos se expresaba el padre Neirot, luego de la batalla de Tucumán:

"ahora es nuestro deber, honrar la memoria de los valerosos é intrépidos patriotas, que acabaron con las armas en las manos, abierto el pecho con muchas y mortales heridas, y cayeron entre motones de cadáveres enemigos. Sabiendo que peleaban por su amabilísima patria, por su libertad, y por la religion de sus padres, prefirieron como Judas

35 Alberto Mario Salas, Crónica y diario, t. II, 338.

36 John Keegan, Historia de la Guerra, 16.

37 Alejandro Rabinovich, La gloria, esa plaga de nuestra, 28 
Macabeo, la muerte gloriosa a una fuga vil y cobarde. ¿Quién duda que la muerte, aunque tan sensible, acarreará infinitas ventajas á la causa publica? Porque conforme escribe el sabio Bossuet, morir con intrepidéz vale muchas veces mas que la victoria" 38 .

Este fragmento nos permite apreciar la construcción de una nueva imagen de la muerte, completamente alejada del tradicional modelo barroco. En la piedad colonial el temor a la muerte tenía un carácter eminentemente positivo, como derivación del "temor de Dios" y como expresión del desengaño o rechazo de las fugaces vanidades mundanas. En efecto, una de las frases más usuales en los testamentos coloniales era la siguiente: "temiéndome de la muerte, que es cosa natural a todo viviente". En el contexto de la guerra, ese "temor a la muerte" adquiría una nueva connotación, mientras que despuntaban en el discurso eclesiástico virtudes hasta entonces típicamente profanas, como la "valentía” y la "intrepidez". En 1821, el clérigo Valentín Gómez aventuraba, apoyándose en San Ambrosio, que "el valor es una virtud más brillante que las demás" 39 . Por su parte, Fray Cayetano Rodríguez, atribuía al general Belgrano las siguientes palabras: "vamos a ellos: lo mismo es morir de cuarenta años, que de sesenta"40. El valor y la intrepidez, hasta entonces vistos con recelo por la Iglesia, se transformaron repentinamente en las "más brillantes" virtudes cristianas. La "muerte gloriosa" e intrépida" marcaba el preludio de la nueva sensibilidad romántica y desplazaba definitivamente al viejo modelo barroco. Lentamente comenzaba a constituirse un culto cívico de los muertos, que excedía y eclipsaba la connotación puramente religiosa. Algo similar había sucedido en la Francia revolucionaria, como señala Michel Vovelle:

"La muerte violenta, aunque se presente a veces con la desnuda brutalidad del homicidio en combate, es a menudo una etapa en el camino a la heroificación. La imagen del héroe que se impone a la posteridad a través de su propia muerte, ya la reciba o se la dé él, corrige en parte

40 Cayetano Rodríguez, "Elogio fúnebre", 159. 
la exaltación de la violencia en bruto. Heroísmo de la muerte recibida gloriosamente, heroísmo de la muerte dada" ${ }^{\prime 4}$.

Mientras que la valentía adquiría un rol preponderante como virtud máxima del ciudadano-soldado, el miedo y la cobardía eran motivo del escarnio y la burla popular. Las severas críticas vertidas hacia la oficialidad veterana durante las invasiones inglesas ilustran este escrutinio colectivo sobre las acciones militares. En sus "Memorias curiosas", Antonio Luis Beruti habla del "atolondrado miedo, $\mathrm{q}^{\mathrm{e}}$ sin mayores fundam. ${ }^{\text {tos }}$ se apoderaron dela imaginacion pusilánime del Virrey" y de "la falta de aguerrida dispocis. ${ }^{\text {" }}$ de los jefes peninsulares". ${ }^{42} \mathrm{El}$ discurso público incitaba a mantener a raya el temor a la muerte, so pena de la burla y el desprecio colectivo. A esto último debió enfrentarse el virrey Sobremonte, presa fácil de las chanzas y mofas de la plebe porteña. A modo de ejemplo, citemos unas coplas anónimas aparecidas hacia comienzos de 1807, bajo el título Preguntas que hace un anciano a un amigo:

"Que dirá el Ayuntamiento

de Córdoba cuando note

al marqués de nombre Zote

en San Isidro de asiento,

y que allí en alojamiento

está su reputación?...

-No sé qué te diga, Antón!

¿Qué dirá el mundo ruidoso

a madama la Cuaresma

cuando ésta saque la resma

con méritos de su esposo

y haga ver que en ser miedoso

cumplió con su obligación?”43

41 Michel Vovelle, "Una revolución en la muerte”, en La mentalidad revolucionaria (Barcelona: Crítica, 1989), 244.

42 Juan Manuel Beruti, "Memorias curiosas", No. 22: 347.

43 Citado en Alberto Mario Salas, Crónica y diario, t. II, 122. 
Sobremonte afirmaba, no sin cierta razón, que había cumplido con las previsiones dispuestas en caso de invasión y que sus órdenes habían tenido el noble propósito de proteger el tren de artillería y preservar el tesoro de la Real Hacienda. Sin embargo, la plebe de Buenos Aires atribuía las acciones del marqués al miedo y a la cobardía. De esta forma, la "opinión pública" ejercía una estrecha vigilancia sobre la conducta militar. El clamor popular planteaba únicamente dos opciones válidas: la victoria o la muerte. Como afirmaba el padre Neirot, mejor era morir de forma heroica que vivir como un cobarde. En similares términos se había expresado Liniers en una proclama de junio de 1807: “Que nuestras voces repitan miles de veces: morir o vencer. Si entre vosotros se hallare (...) algún alma débil (...) que se le cambien las armas por una rueca, y que una muerte afrentosa sea el premio de la cobardía, si la hubiere"

Luego de la desastrosa batalla de Huaqui, en 1811, el gobierno de Buenos Aires aplicó una medida particularmente significativa. Al mismo tiempo que se publicaba en la Gaceta una lista compuesta por los oficiales sospechados de cobardía, se mandaba inscribir en la columna del 25 de mayo los nombres de los caídos en aquel trágico combate. El imperativo de la guerra era explicito: "que vuestro último deseo sea, que vuelvan vencedores, o que mueran como Lucena, Vélez, y Bozo, en los brazos de la gloria y de la libertad"45. La "Marcha Patriótica", aprobada por la Asamblea Constituyente de 1813, anunciaba también este principio con extrema contundencia: "coronados de gloria vivamos, /o juremos con gloria morir". La gloria y la heroicidad tenían su antítesis en el miedo a la muerte, cuyas consecuencias más directas eran la fuga y la cobardía. Ya no había lugar para la muerte lenta y reposada de los tiempos pretéritos.

\section{LA MUERTE DEL “OTRO”: ENTRE EL RENCOR Y LA MISERICORDIA.}

"Aquí yace el famoso Regimiento

Nombrado del inglés, 71, jamás vencido de enemigo alguno, que en lides mil salió con lucimiento"*4.

44 Alberto Mario Salas, Crónica y diario, t. II, 289.

45 Alejandro Rabinovich, Anatomía del pánico.

46 Alberto Mario Salas, Crónica y diario, t. I, 272. 
Hemos señalado que la muerte del soldado era honrada y glorificada por la sociedad guerrera, aunque en el fragor de la batalla también podía inducir al pánico y al desaliento. Pero, ¿qué sucedía con la muerte del enemigo? ¿En qué términos era enunciada y conceptualizada? ¿Qué tratamiento recibían los cadáveres insepultos del adversario? ¿Se detenía la guerra con la derrota del enemigo o se extendía más allá de la muerte? El discurso eclesiástico promovía la misericordia y la "religiosa moderación” con los vencidos, sin embargo, ésta no siempre era la postura más extendida. La actitud ante la muerte del "otro", del enemigo, variaba en una multiplicidad de formas: la piedad y conmiseración hacia el cuerpo muerto del adversario convivía con el encarnizamiento póstumo, la burla y la indiferencia. Cada una de estas actitudes expresaba sentimientos, ansiedades, inquietudes y emociones diferentes. Estas distintas respuestas revelan que no existía una única forma de enfrentar y asumir la muerte en tiempos de guerra.

Tanto la Reconquista de 1806 como la Defensa de 1807 dejaron una multitud de cadáveres tirados por las calles e inmediaciones de la ciudad. La tarea de recoger estos cadáveres y darles sepultura fue ejecutada por los carros de limpieza, que depositaron los cuerpos en fosas comunes, en las diferentes "zanjas" o "huecos" dispersos por la traza de Buenos Aires. Sin embargo, los oficiales ingleses de mayor graduación fueron objeto de solemnes honras fúnebres, que contaron con la asistencia de los principales jefes porteños y autoridades eclesiásticas y civiles. Como los protestantes no podían ser enterrados "en sagrado", se los inhumaba en el atrio de las iglesias o se los llevaba al Retiro. Éste último fue el caso de los oficiales Kennet y Mitchel, cuyo cortejo fue encabezado por Liniers y sus cuerpos escoltados por soldados españoles e ingleses, al son de una caja y dos clarinetes ${ }^{47}$. También en Montevideo se realizaron funerales a los oficiales ingleses, con todos los ritos propios de la fe anglicana. En un diario titulado Notes of the Viceroyalty of the Rio de La Plata se describe una de estas exequias de la siguiente forma:

"[se enterró en el atrio de San Francisco], frente a la capilla, con honores militares, a un oficial inglés muerto a consecuencia de las heridas

47 Alberto Mario Salas, Crónica y diario, t. I, 273. 
recibidas durante el asalto de esta ciudad. Otro oficial leyó el servicio fúnebre. El populacho reunido en torno para observar la ceremonia miraba con curiosidad y azoramiento. Los frailes se miraban entre sí y sus rostros reflejaban asombro y piedad mezclados con desdén. Era éste el primer funeral herético al que asistían"48.

Otro caso particularmente interesante es el del teniente coronel Edward Butler, fallecido el 23 de julio de 1807 y velado en el fuerte, con asistencia del gobernador y demás jefes militares. El cadáver de Butler fue sepultado en el patio del cuartel del regimiento de patricios, tal como éste había pedido ${ }^{49}$. Según Francisco Saguí, el cuerpo del militar británico se encontraba sepultado bajo un monumento fúnebre que se conservó hasta 1818: "era un cenotafio abovedado cuadrilongo sobre el cual se elevaban dos agujas piramidales como de tres varas de altura. (...) Lo más verosímil fue que él mismo había pedido ser sepultado en el cuartel de los valientes que lo habían rendido" 50 .

Luego de la batalla de Salta y una vez acordada la rendición de las tropas realistas comandadas por el brigadier Juan Pío Tristán, el general Belgrano dispuso que fueran enterrados los muertos de ambos ejércitos en una misma fosa común. Sobre la sepultura, en el campo de Castañares, se colocó una gran cruz de madera con la siguiente inscripción: "Aquí yacen los vencedores y vencidos el 20 de febrero de 1813" 51 . La inhumación de los caídos de ambos ejércitos en un mismo sepulcro no es un dato menor. No sabemos a ciencia cierta qué tan frecuente era esta práctica, aunque los contemporáneos lo presentan como un hecho excepcional. En su oración fúnebre de 1821, Valentín Gómez destacaba este comportamiento y lo atribuía al carácter religioso del general: "él se

48 Alberto Mario Salas, Crónica y diario, t. II, 134-135, n. 67.

49 Salas señala que el muerto en cuestión no era Butler sino el coronel Kington. Alberto Mario Salas, Crónica y diario, t. II, 359. El "Diario de un soldado" también menciona el episodio, aunque no da cuenta de su identidad. Diario de un soldado [1806-1809] (Buenos Aires: Archivo General de la Nación, 1960), 184.

50 Francisco Saguí, Los últimos cuatro años de la dominación española en el antiguo virreinato del Río de la Plata, desde 26 de junio de 1806 hasta 25 de mayo de 1810: memoria histórica familiar (Buenos Aires: Imprenta Americana, 1874), 79.

51 Bartolomé Mitre, Historia de Belgrano y de la independencia argentina (Buenos Aires: Imprenta y Librería de Mayo, 1876), t. I, 523-524. 
arroja, es verdad, con ardor a los combates; pero en el momento en que es dueño de la victoria, lamenta las desgracias del vencido, y deja caer la espada de su mano para emplearla en su socorro"52. Quienes formaban parte del ejército de Belgrano también destacaban el recogimiento y pesar con que se vivieron esos días. Según Dámaso Uriburu, "era tan profundo el sentimiento de consternación que se había apoderado de los ánimos de los guerreros y de los vecinos por la espantosa carnicería que presenciaron, que no hubo la menor demostración de alegría pública"53.

Sin embargo, no siempre imperaban las "leyes de la guerra". Junto con estas muestras de piedad y misericordia, convivían actitudes mucho menos "honrosas" o, como las denomina Keegan, de "violencia impropia" 54 . La mutilación de cadáveres parece haber sido una práctica relativamente frecuente en el contexto de las guerras rioplatenses. En noviembre de 1806, el virrey Sobremonte tomó conocimiento de que se había mutilado el cuerpo de un soldado británico cortándole las orejas. En el Diario de un soldado leemos: "Pareze que Pofan a pasado un oficio a S. E. quejándose que sabe que los Españoles an cortado las orejas y otros \&cc. a los ingleses muertos despues de la rendizion de la reconquista" ${ }^{55}$. En carta al teniente coronel Juan Moreno, que operaba en la zona de San Carlos (en la Banda Oriental), el virrey ordenó que se hiciera comprender a la tropa "lo abominable de este procedimiento y que el que lo ejecute será castigado severamente por las leyes de la guerra y la humanidad misma" 56 . Unos meses más tarde, el almirante Stirling dejaba asentado en su diario que el gobernador de Montevideo, Pascual Ruiz Huidobro, había admitido en una misiva "la barbaridad que se ha cometido al mutilarse heridos ingleses", aunque lo atribuía a los indios y mulatos y no a las tropas españolas. "Yo pienso que es malo de una manera o de otra", escribía el almirante ${ }^{57}$.

52 Valentín Gómez, "Elogio fúnebre", 110.

53 Cayetano Bruno, La Virgen Generala, 243.

54 John Keegan, El rostro, 26.

55 Diario de un soldado [1806-1809], 81.

56 Alberto Mario Salas, Crónica y diario, t. I, 430.

57 Alberto Mario Salas, Crónica y diario, t. II, 39. 
La mutilación del cuerpo muerto del enemigo podía revestir múltiples significados de acuerdo con los diferentes contextos y circunstancias en que había ocurrido. Para algunos, el cuerpo yerto del soldado abatido era la representación más cercana de sus miedos y rencores, de sus frustraciones, desvelos y pesadillas. Para otros, el cadáver del enemigo era la máxima expresión de la victoria alcanzada a costa de tantos esfuerzos, privaciones y peligros. En cierta forma, también aquellos cuerpos sin vida podían transformarse en un trofeo que permitiera acreditar la hazaña alcanzada. Paseando por la ciudad de Lima en 1848, Gerónimo Espejo se encontró con un negro veterano de la campaña de San Martín. Para demostrar su efectiva participación en la guerra, el negro sacó de su bolsillo un bollo de papel, bajo el cual "conservaba los "bigotes de un talavera", soldado español de élite a quien luego de voltear de un bayonetazo y rematar de un balazo, le había cortado el bigote con labio y todo". ${ }^{58}$ Este curioso testimonio constituye una pequeña muestra de cómo el cadáver del enemigo podía transformarse también en un trofeo o botín de guerra.

La exposición del soldado frente al espectáculo omnipresente de la muerte hacía que ésta perdiera sentido, hasta transformarse en una vivencia cotidiana, una contingencia más, un accidente casi banal. Esta actitud sólo podía tener lugar dentro de un marco de violencia persistente, que excedía por mucho al campo de batalla. Como señala Rabinovich,

“esta violencia cotidiana, este peligro constante, modelaba poderosamente las actitudes de la población local en todo aquello que concernía a la muerte infligida o recibida. A medida que la guerra civil avanzaba, la muerte se banalizaba al punto de que los cadáveres permanecían en el mismo lugar durante días enteros, las ejecuciones se hacían de manera sumaria y las facciones hacían alarde de una crueldad crecientemente refinada" $"$. 
Algunos episodios en particular ilustran con toda claridad esta banalización de la muerte, al igual su transformación en una instancia más del conflicto bélico. Sirva como ejemplo el siguiente caso:

"Algunos meses después de la batalla de Cepeda entre las fuerzas de Santa Fe y las de Buenos Aires, en 1820, José Celedonio Balbín pasó por una posta próxima al campo de batalla. Una veintena de cadáveres humanos yacían amontonados en una esquina del patio. Comidos por los cerdos y las ratas que infestaban el establecimiento, los cuerpos ya estaban irreconocibles, convertidos en huesos. Balbín le pide al dueño de la posta que los entierre. Este se rehúsa: sentía placer al mirarlos, ya que todos ellos eran porteños"

Además de la indiferencia, la muerte y derrota del enemigo también podían convertirse en un motivo de burla y escarnio público. El 13 de agosto de 1806, la pared de la prisión del cabildo amaneció pintada con el siguiente "epitafio":

Aquí yace el famoso Regimiento

Nombrado del inglés, 71,

jamás vencido de enemigo alguno,

que en lides mil salió con lucimiento.

Aquí yace postrado su ardimiento

a la fuerza y valor de unos soldados, que sin brillo, sin lustre y desastrados, abatieron su orgullo en un momento.

Llorará la Inglaterra esta desgracia, sirviendo de escarmiento a su osadía, al saber sucumbieron por audacia cerca de dos mil hombres... que manía, intentar dominar su ineficacia, del argentino el brío y su valentía ${ }^{61}$.

61 Alberto Mario Salas, Crónica y diario, t. I, 272. 
Todos estos mecanismos retórico-discursivos permitían reafirmar la victoria alcanzada sobre el enemigo, así como su carácter permanente e inapelable; tanto como la propia muerte. A pesar de que las "leyes de la guerra" y la "moderación religiosa" aconsejaban una actitud de mesura ante el enemigo abatido, la lucha, los odios y las venganzas no siempre culminaban con la muerte del adversario. Aunque muchas veces la muerte concitaba la magnanimidad y la empatía del vencedor, en otras ocasiones, ésta se proyectaba como una continuación de la guerra, de los enconos y los conflictos. Dentro de los grandes ejércitos, estas formas de "violencia impropia" eran consideradas particularmente peligrosas, ya que subvertían el principio de la "mínima fuerza necesaria" e implicaban un desafío a los mecanismos de mando y de control. Como señala Keegan, el sistema disciplinar sólo puede seguir funcionando "si los oficiales obedecen escrupulosamente las reglas y los procedimientos" 2 . Estos "les proporcionan valores fijos a todos los individuos y grupos en el campo de batalla (...), imponen límites estrictos al uso de la violencia, y determinan en qué circunstancias ha de ejercerse"63. No ha de sorprender que para fuerzas altamente fragmentarias, irregulares y heterogéneas, como las rioplatenses, este conjunto de reglas y "valores fijos" resultara mucho más difuso. A medida que la guerra de independencia devenía en una guerra civil, el límite entre la violencia legítima y la ilegítima se volvía cada vez más borroso.

\section{CONSIDERACIONES FINALES:}

Es innegable que el continuado estado de guerra en que se vio sumido el Río de La Plata a comienzos del siglo XIX desencadenó una profunda y duradera transformación en los más variados aspectos de la vida social. Las consecuencias del proceso de militarización eran evidentes, tanto en materia política como económica. Sin embargo, no resulta sencillo determinar en qué medida estas transformaciones incidieron en la mentalidad del hombre rioplatense y, en particular, sobre las actitudes colectivas ante la muerte. ¿Se acostumbró la sociedad a convivir con las incertidumbres y peligros de la guerra? ¿Perdió la muerte parte de

\footnotetext{
62 John Keegan, El rostro, 26.
}

63 John Keegan, El rostro, 26. 
su carácter traumático, para transformarse en una vivencia casi banal? ¿Impulsó la guerra un nuevo culto cívico y patriótico, que tendió a reemplazar al religioso? ¿Cómo se pasó del miedo reverencial, propio de la piedad barroca, a la nueva máxima de "morir con intrepidez"?

Por lo pronto, no es arriesgado afirmar que el miedo a la muerte es una de las grandes constantes de la experiencia guerrera, aunque las actitudes y reacciones frente a ésta varían dentro de cada sociedad y coyuntura histórica. Para los hombres de comienzos del siglo XIX, el imaginario en torno a la muerte aún conservaba muchos vestigios de la vieja pastoral barroca. El infierno, la condenación eterna y la "mala muerte" no eran entidades abstractas. Era necesario para el soldado saber que combatía una "guerra del agrado del Señor" y que contaba con la protección divina de su lado. Tanto Liniers como Belgrano y San Martín eran plenamente conscientes del papel que jugaban estos factores inmateriales en la psiquis del combatiente. Ellos buscaron presentarse como fieles ejecutores de la voluntad divina y propiciar su protección a través de ceremonias cuidadosamente diseñadas. De la misma forma, los soldados que actuaban bajo sus órdenes solían llevar consigo escapularios, rosarios y medallas, a modo de talismanes y amuletos protectores.

La sociedad guerrera procuró aplacar los efectos traumáticos de la muerte, tanto en un plano individual como colectivo. Un conjunto de mecanismos disciplinarios y de control tendían a mantener a raya el miedo a la muerte, así como las consecuencias funestas en que éste podía derivar. El miedo a ser considerado un cobarde, la confianza en la protección divina, las lealtades recíprocas entre compañeros, empujaban al soldado hacia delante y hacían que el contacto permanente con la muerte y el temor que éste engendraba no llegaran al punto de transformarse en pánico. Paralelamente, la conmemoración y exaltación de los caídos permitía inflamar los ánimos y apuntalar el consenso social en tiempos de guerra, así como fortalecer la identidad y cohesión interna de cada uno de los regimientos. Por otro lado, las mutilaciones y otros actos "impropios" demuestran que el uso de la violencia no siempre obedecía a los límites impuestos por las "leyes de la guerra". 
Los prolongados conflictos bélicos que se desataron en el Río de la Plata impulsaron una transformación que ya se encontraba en marcha. $\mathrm{Al}$ temor reverencial que infundía la muerte barroca comenzaba a oponérsele el ideal romántico de la muerte heroica e intrépida. Los valores sociales que regían la percepción y actitud ante la muerte se encontraban sometidos a una profunda transformación. El discurso público comenzaba a entronizar a los caídos en un nuevo "panteón cívico", que poco tenía que ver con la vieja tradición religiosa, aunque se sirviera de su simbología y apelara también al clero como portavoz autorizado. Con la guerra, la muerte se había vuelto más cercana y apremiante y al mismo tiempo la sociedad había procurado cubrir su rostro más sombrío bajo las luces de la gloria y el heroísmo. Al igual que Jano, el dios bifronte de los romanos, la muerte del guerrero poseía dos caras: una lúgubre y aterradora, la otra sublime y luminosa.

\section{Bibliografía}

\section{Fuentes primarias}

Archivo General de la Nación Argentina (AGNA), Buenos Aires - Argentina. Sala VII, Biblioteca Nacional.

Beruti, Juan Manuel. "Memorias curiosas". Revista de la Biblioteca Nacional No. 22-37 (1942-1946).

Diario de un soldado (1806-1809). Buenos Aires: Archivo General de la Nación, 1960.

Gómez, Valentín. "Elogio fúnebre del benemérito ciudadano Manuel Belgrano, ilustre miembro de la Primera Junta Gubernativa..." [1821]. En El clero argentino, de 1810 a 1830, t. II. Buenos Aires: Imprenta de M. A. Rosas, 1907, 93-115.

Paz, José María. Memorias póstumas. Buenos Aires: Imprenta de la Revista, 1855.

Rodríguez, Cayetano. "Elogio fúnebre del benemérito ciudadano, ilustre miembro de la Primera Junta Gubernativa... Don Manuel Belgrano" [1821]. En El clero argentino, de 1810 a 1830, t. II. Buenos Aires: Imprenta de M. A. Rosas, 1907, 117-176.

Nieremberg, Juan Eusebio. Partida a la eternidad. Madrid: Imprenta de Agustín Fernández, 1714. 
Neirot, Juan Antonio. Oración fúnebre que en las solemnes exequias de los valientes soldados que murieron en la defensa de la patria en la ciudad del Tucumán... Buenos Aires: Imprenta de Niños Expósitos, 1812.

Saguí, Francisco. Los últimos cuatro años de la dominación española en el antiguo virreinato del Río de la Plata, desde 26 de junio de 1806 hasta 25 de mayo de 1810: memoria histórica familiar. Buenos Aires: Imprenta Americana, 1874.

\section{Fuentes secundarias}

Ariès, Philippe. El hombre ante la muerte. Madrid: Taurus, 1984.

Barral, María Elena. De sotanas por la Pampa. Religión y sociedad en el Buenos Aires rural tardocolonial. Buenos Aires: Prometeo, 2007.

Bruno, Cayetano. La Virgen Generala. Estudio documental. Rosario: Ediciones Didascalia, 1994.

Cruz de Amenábar, Isabel. La Muerte: Transfiguración de la Vida. Santiago de Chile: Ediciones Universidad Católica de Chile.

Fernández, María Alejandra. "Muerte y pedagogía política durante la Revolución: Buenos Aires, 1810-1812”. En Muerte, política y sociedad en la Argentina, editado por Sandra Gayol y Gabriel Kessler. Buenos Aires: Edhasa, 2015, 33-59.

Gómez, Fernando. Guerra y movilización popular en tiempos revolucionarios. Una perspectiva desde la Batalla de Tucumán. Buenos Aires: Foros de historia política, 2013. http:// historiapolitica. com/datos/foros/foro_sectpopulares_gomez.pdf

Gruzinski, Serge. La guerra de las imágenes. De Cristóbal Colón a Blade Runner (1942-2019). México: Fondo de Cultura Económica, 1994.

Halperín Donghi, Tulio. "Militarización Revolucionaria en Buenos Aires, 1806-1815”. En El ocaso del orden colonial en Hispanoamérica. Buenos Aires: Sudamericana, 1978, 123-158.

Halperin Donghi, Tulio. Revolución y Guerra. Formación de una élite dirigente en la Argentina criolla. Buenos Aires: Siglo XXI, 1994.

Keegan, John. Historia de la Guerra. Barcelona: Planeta, 2005.

Keegan, John. El rostro de la batalla. Madrid: Turner, 2016. 
Mitre, Bartolomé. Historia de Belgrano y de la independencia argentina. Buenos Aires: Imprenta y Librería de Mayo, 1876.

Ortemberg, Pablo. "Las vírgenes generalas: acción guerrera y práctica religiosa en las campañas del Alto Perú y el Río de la Plata (18101818)". Boletín del Instituto de Historia Argentina y Americana “Dr. Emilio Ravignani”" No. 35-36 (2011-2012): 11-42.

Rabinovich, Alejandro. "La gloria, esa plaga de nuestra pobre América del Sud. Ethos guerrero en el Río de la Plata durante la Guerra de la Independencia, 1810-1824". Nuevo Mundo Mundos Nuevos, Débats (2009).

Rabinovich, Alejandro. La société guerrière. Pratiques, discours et valeurs militaires dans le Rio de la Plata (1806-1852). Rennes: Presses Universitaires de Rennes [en ligne], 2017.

Rabinovich, Alejandro. Anatomía del pánico. La batalla de Huaqui o la derrota de la Revolución (1811). Buenos Aires: Sudamericana, 2017.

Salas, Alberto Mario. Crónica y diario de Buenos Aires: 1806-1807, t. I-II. Buenos Aires: Ediciones Biblioteca Nacional, 2013.

Vovelle, Michel. "Una revolución en la muerte". En La mentalidad revolucionaria. Barcelona: Crítica, 1989, 233-248.

Para citar este artículo: Roca, Facundo. "La militarización de la muerte: guerra y religión en el Río de la Plata a comienzos del siglo XIX (1806-1820)", Historia Caribe Vol. XV No. 36 (Enero-Junio 2020): 205234 DOI: http://dx.doi.org/10.15648/hc.36.2020.9 